ISSN 1999-4915

www.mdpi.com/journal/viruses

Review

\title{
Flavivirus-Mosquito Interactions
}

Yan-Jang S. Huang ${ }^{1,2}$, Stephen Higgs ${ }^{1,2}$, Kate McElroy Horne ${ }^{2}$ and

Dana L. Vanlandingham ${ }^{1,2, *}$

1 Department of Diagnostic Medicine and Pathobiology, College of Veterinary Medicine, Kansas State University, Manhattan, KS 66506, USA; E-Mails: yshuang1985@ksu.edu (Y.-J.S.H.); shiggs@bri.ksu.edu (S.H.)

2 Biosecurity Research Institute, Kansas State University, Manhattan, KS 66506, USA;

E-Mail: kmhorne@ksu.edu

* Author to whom correspondence should be addressed; E-Mail: dlvanlan@vet.ksu.edu;

Tel.: +1-785-532-1369; Fax: +1-785-532-0973.

External Editor: Rollie Clem

Received: 1 October 2014; in revised form: 17 November 2014 / Accepted: 20 November 2014 / Published: 24 November 2014

Abstract: The Flavivirus genus is in the family Flaviviridae and is comprised of more than 70 viruses. These viruses have a broad geographic range, circulating on every continent except Antarctica. Mosquito-borne flaviviruses, such as yellow fever virus, dengue virus serotypes 1-4, Japanese encephalitis virus, and West Nile virus are responsible for significant human morbidity and mortality in affected regions. This review focuses on what is known about flavivirus-mosquito interactions and presents key data collected from the field and laboratory-based molecular and ultrastructural evaluations.

Keywords: flavivirus; Aedes mosquito; Culex mosquito; hemorrhagic fever

\section{Introduction to the Flaviviruses}

The family Flaviviridae, named from the Latin "flavus" for the hallmark jaundice caused by infection with yellow fever virus (YFV), is comprised of the genera Flavivirus, Pestivirus, and Hepacivirus. Mosquito-borne viruses make up a large portion of this family and will be referred to as "flaviviruses" throughout this review. Flaviviruses are encoded by a single-stranded, positive sense 
RNA genome approximately $11 \mathrm{~kb}$ in length. The genome is a single open reading frame encoding 10 viral proteins that are cleaved co- and post-translationally from the polyprotein, the capsid (C), membrane (M), and envelope (E) structural proteins and the nonstructural (NS) proteins 1, 2A, 2B, 3, $4 \mathrm{~A}, 4 \mathrm{~B}$, and 5 . The polyprotein is flanked by 5 ' and 3 ' non-coding regions [1].

As described below, arboviruses within this genus are transmitted by a variety of mosquito species as well as ixodid and argasid ticks. This review will focus on mosquito-virus interactions of four medically important flaviviruses: YFV, dengue virus (DENV) serotypes 1-4, Japanese encephalitis virus (JEV), and West Nile virus (WNV). The geographic distribution of viruses in this family is very broad, and consistent with other arboviruses, the distribution of each virus mirrors that of its vector. It has been estimated that over half of the global population is at risk for infection with one of four dengue virus serotypes (DENV-1, -2, -3, and -4) [2], and YFV, DENV, JEV, and WNV collectively cause millions of infections and tens of thousands of deaths each year [3]. Syndromes following human infection with flaviviruses range from clinically inapparent asymptomatic infections to severe, and sometimes, fatal disease, including hemorrhagic manifestations of severe YFV and DENV infection and encephalitis caused by infection with JEV or WNV. Whereas humans are dead-end hosts for many arboviruses, including JEV and WNV [4], they play a large role in the transmission cycles of YFV and DENV [5-7].

\section{Classification and Evolution}

The flaviviruses are subgrouped into nine serogroups, five of which contain important human pathogens. Although mutation rates of up to $10^{-4}$ substitutions per nucleotide can be attributed to the lack of proofreading capacity of the RNA polymerase, flavivirus evolution is constrained by the need to replicate in invertebrate vectors and vertebrate hosts, as has been demonstrated for the dengue viruses [8]. Based on the host range and choice of vector species, there are four distinct groups: mosquito-borne, tick-borne, no known vector viruses, and insect specific (mosquito only) viruses, with the mosquito-borne group further subdivided into Old World viruses primarily associated with Aedes spp. mosquitoes that cause hemorrhagic disease syndromes such as YFV and DENV, Old and New World viruses primarily associated with Culex spp. mosquitoes that cause encephalitic disease syndromes, and insect-specific viruses [9,10]. The Flavivirus genus has been hypothesized to have emerged from mammalian viruses with no arthropod vector and the mosquito- and tick-borne flaviviruses emerged from Africa [11,12]. This hypothesis is further supported by the phylogeny of flaviviruses showing no known vector viruses are considered ancestral to vector-borne viruses $[13,14]$. However, the actual emergence of flaviviruses in evolution remains elusive. Proposed theories explaining host preference and vector choice have not been convincing and can further be complicated by the fact that flaviviruses often infect multiple vertebrate hosts and are transmitted by multiple vector species. Earlier ecological studies suggest the narrow host range of flavivirus under the JEV serocomplex is characteristic of being more evolutionarily primitive and the use of a single host by DENV and YFV is a more recent development [15]. Phylogenetic analyses also indicate the more recent emergence of JEV-serocomplex flaviviruses as compared to other viruses under the DENV and YFV serocomplexes [14]. In contrast to mosquito-borne flaviviruses that alternate between vertebrate hosts and arthropod vectors, the group of insect-specific flaviviruses has been demonstrated to evolve 
and appear in the family multiple times, leading to two major clades associated with Culex spp. and Aedes spp. mosquitoes [16]. Geographically, the insect-specific flaviviruses co-circulate with pathogenic mosquito-borne flaviviruses. It remains to be seen if the co-infection of insect-specific flaviviruses will change the vector competence of mosquitoes for pathogenic flaviviruses [17].

The prototypic flavivirus, YFV, has evolved into five genotypes, three of which are circulating within the urban cycle in different regions of Africa, and two genotypes are found in Latin America [5,18]. The introduction of YFV into Latin America from Africa likely occurred during the slave trade approximately 300-400 years ago [19]. The sylvatic strains of YFV were distinct from other currently circulating isolates in their growth behaviors in mammalian and insect tissue culture, which is likely reflective of a lack of host adaptation and a difference in ecological conditions [20].

The origin of DENV still remains elusive even though the viruses and ecological systems that support the sylvatic strain of DENV have been discovered both in Asia and West Africa [21]. Historically, the determination of genotypes within each serotype was based on the cut off of $6 \%$ of genetic divergence [22]. Currently, there are five genotypes defined under DENV-1 mainly representing the locations of the original isolations [23-25]. DENV-2 was comprised of six genotypes, with the Cosmopolitan genotype showing the widest geographic distribution in the majority of the tropical region [26]. DENV-3 and DENV-4 have five and four known genotypes, respectively [27-32].

The emergence of JEV was proposed to have occurred in Southeast Asia approximately 350 years ago [33]. There have been four circulating genotypes of JEV recognized with consistent results from different molecular virological tools such as RNase T1 mapping and genomic sequences. Recently, the re-emergence of genotype $\mathrm{V}$ was reported in China and Korea following a nearly six decade long absence [34]. With the clusters of genotypes separated by distinct geographic locations, the plausible explanation for the presence of different genotypes in different areas is likely due to the evolution in different mosquitoes and amplification hosts. However, the differences among genotypes I-III are limited to less than $12.0 \%$ and $3.5 \%$ at the nucleotide and amino acid levels, receptively [33]. Historically, genotype I has been found primarily in Australia, Japan, Korea, Northern Thailand, and Cambodia. Genotype II has been isolated from Southeast Asian countries, especially Malaysia and Indonesia, and was reported to be associated with the first incursion of JEV into Australia in 1995 followed by the isolation of genotype I in Northern Australia in 1998 [35,36]. Genotype III constitutes the largest number of isolates among all genotypes and is found throughout Asia. Genotype IV is ancestral to all circulating genotypes and shows the largest antigenic and phylogenetic differences compared to other genotypes. Although phylogenetic evidence has demonstrated that genotype I has displaced genotype III and become the predominant genotype throughout Asia since the 1990s, there has not been definitive laboratory evidence showing the relative selective advantage of specific genotypes in amplification hosts or arthropod vectors [37].

WNV is another important virus in the JEV serocomplex and circulates in different geographic regions. There are a total of five lineages of WNV which have been discovered, with lineage 1 and 2 having the highest public health significance [38]. Among all five lineages, lineage 1 has the widest geographic distribution and can be found worldwide. In 1999, the introduction of WNV lineage 1 in the United States led to the establishment of New York 99 (NY99) genotype which was found related to an isolate in Israel [39]. As a consequence of continuous evolution, there have been at least three additional genotypes identified in North America: the southeastern Coastal Texas genotype, the North 
America/WN 2002 genotype, and the Southwest/WN 2003 genotype [40-42]. The southeastern Coastal Texas genotype is thought to now be extinct.

Multiple factors can drive the evolution of flaviviruses and create complexity in virus-vector and virus-host interactions [43]. Specific genotypes of the same virus can possess advantages in infectivity, replication, and dissemination in arthropod vectors, which often result in the displacement of other genotypes in nature [37,44-46].

\section{Flavivirus Epidemiology}

Mosquito-borne flaviviruses are transmitted in nature in one or more distinct or overlapping cycles that include a mosquito vector, generally Aedes spp. mosquitoes for YFV and DENV and Culex spp. mosquitoes for JEV and WNV, and a mammalian or avian host. Transmission between mosquitoes and vertebrate hosts is termed horizontal transmissions and causes disease in vertebrates. In contrast to horizontal transmission, mosquito-borne flaviviruses can be maintained in the environment through vertical, i.e., transgenerational, transmissions which allow the spread of flaviviruses solely in mosquitoes [47]. The most direct evidence supporting the vertical transmission of mosquito-borne flaviviruses is derived from the isolation of virus from infected larvae presumably through transovarial transmission [48]. This observation is consistent with the detection of viral antigens in ovarian tissues of infected mosquitoes [49-53].

Both YFV and DENV are transmitted in an urban cycle between humans and Ae. aegypti. YFV occurs in enzootic cycles in Africa and the Americas and DENV occurs in enzootic cycles in Africa and Asia. The enzootic cycles of DENV and YFV are mainly maintained between arboreal Aedes spp. [54]. In the past decade, epidemics associated with urban cycles of YFV transmission have largely been eliminated in the Americas. However, YFV remains a re-emerging threat because deaths caused by epizootic outbreaks are still reported [55-62]. JEV is widespread across Asia and the Pacific region where it is maintained in an enzootic cycle in Asia between Culex spp. mosquitoes and pigs or aquatic birds as amplifying hosts; unlike YFV and DENV, humans are dead-end hosts as they generally do not mount sufficient viremia to infect mosquitoes [63-65]. WNV, the most widely distributed of the flaviviruses, is also maintained in an enzootic cycle in affected regions between Culex spp. mosquitoes and birds, with humans and horses serving as dead-end hosts [65,66]. The existence of mammalian and avian reservoir hosts for these viruses makes elimination difficult or impossible, so prevention and control must focus on vaccination as well as vector control programs.

Although large YFV epidemics occurred in the 17th, 18th, and 19th centuries and disease reports consistent with YFV date back to the late 15th century [5], the mechanism of YFV transmission was not identified until 1900. Carlos Finlay first proposed a link between YFV and mosquitoes but failed to account for the extrinsic incubation period, the time between uptake of an infectious meal by a mosquito and subsequent transmission by bite, in his evaluations [67]. The Reed Commission composed of Reed, Agramonte, Carroll, and Lazear established the agent that caused YF disease was a filterable agent (not a bacterium or parasite) that was transmitted by mosquitoes [68-70]. This discovery substantially impacted public health, particularly in the Americas where the implementation of control programs for Ae. aegypti resulted in the elimination of urban YFV and DENV, which shares the same vector [7]. Around the same time, YFV transmission in Francophone Africa was reduced by 
mass vaccination of human populations with vaccines developed by the French (French Neurotropic Vaccine, FNV) and the Rockefeller YF Commission (17D) through multiple passage of wild-type parental strains through various tissues to derive attenuated viruses [71,72]. Whereas FNV was discontinued in 1971 due to cases of neurotropic disease after vaccination, the YFV 17D vaccine is considered to be one of the safest and most efficacious vaccines available and is still in use today [5]. The only other arbovirus with a vaccine licensed for human use is JEV, which is an inactivated vaccine. Considerable effort has been directed toward the development and testing of live attenuated, recombinant, or inactivated vaccines for DENV and WNV, but none have been licensed for human use. There are no treatments for any of the flavivirus diseases and therapy is mainly supportive. Consistent with other arboviruses, the primary means of control and prevention involves mosquito control, but large mosquito control programs are difficult to maintain, especially in resource-poor countries which are overwhelmingly affected by these diseases. After great success eradicating Ae. aegypti from most parts of the Americas, as a result of programs initiated by the Pan American Health Organization, the failure to maintain control efforts resulted in a resurgence of the mosquito and a return of the viruses it vectors [7].

\section{Selected Medically Important Flaviviruses in Mosquitoes}

\subsection{Yellow Fever Virus}

Disease caused by YFV may be subclinical, mild and non-specific, or severe with jaundice, hemorrhage, and death. The first phase of disease, which starts 3-6 days after the bite of an infective mosquito, is non-specific and may include fever, malaise, dizziness, nausea and vomiting, headache, lumbosacral pain, and myalgia. The remission phase either proceeds recovery or may be followed by a period of intoxication characterized by headache, vomiting, jaundice, enlargement of the liver and hemorrhage [6]. Greater than $90 \%$ of cases occur in sub-Saharan Africa [73], where the virus exists in a jungle cycle featuring Ae. africanus, an urban cycle featuring Ae. aegypti, and an intermediate sylvatic cycle that links the two in which tree-hole breeding mosquitoes such as Ae. africanus, Ae. bromeliae, Ae. luteocephalus, Ae. furcifer, Ae. metallicus, Ae. opek, Ae. taylori, Ae. vittatus, Ae. simpsoni, and Ae. kenysesis transmit virus to humans and non-human primates [6,73,74]. In South America, the jungle cycle is propagated by Haemagogus janthinomys and Sabethes chloropterus mosquitoes and humans and non-human primates [6], and urban transmission of virus to humans by Ae. aegypti only occurs sporadically. The transmission cycles in Africa and South America are summarized in Figure 1. The virus is absent in Asia and Australia, although mosquitoes in both regions are susceptible to the virus $[75,76]$.

The vast majority of what is known about YFV interactions with mosquitoes has come from studies of the virus in its primary vector, Ae. aegypti. The extrinsic incubation period is 9-12 days; however higher temperatures result in more rapid dissemination of virus which shortens the incubation period [77]. Experiments conducted by Davis and Shannon (1928) determined infectious YFV was present in all three mosquito body sections before transmission occurred, including the midguts, hindguts, legs, salivary glands, and ovaries. Later experiments confirmed YFV was able to be transmitted transovarially at a very low rate with only $0.2 \%$ of eggs infected $[78,79]$. Even at this low 
rate, transovarial transmission may allow virus survival in unhatched eggs during dry or cool periods [6,73]. Other studies found mosquito mortality was not higher in YFV-infected as compared to uninfected Ae. aegypti which indicates the virus does not have a deleterious effect on the mosquito. Other experiments found mosquitoes could be infected in the laboratory as long as 110 days after emergence and transmit YFV up to 128 days after infection [80]. In Ae. albopictus examined by immunofluorescence assay, YFV was first detected in the posterior midgut, followed by the brain, fat body and salivary glands, but was never detected in the ovaries [81]. YFV tissue tropisms examined by immunohistochemical staining of sectioned Ae. aegypti found wild-type YFV infection in the anterior and posterior midgut, cardia, fat body and nervous tissues in all three segments, and salivary glands of Ae. aegypti within 14 days of infection, whereas infection of Ae. aegypti with the attenuated 17D vaccine strain was limited to the midgut [50].

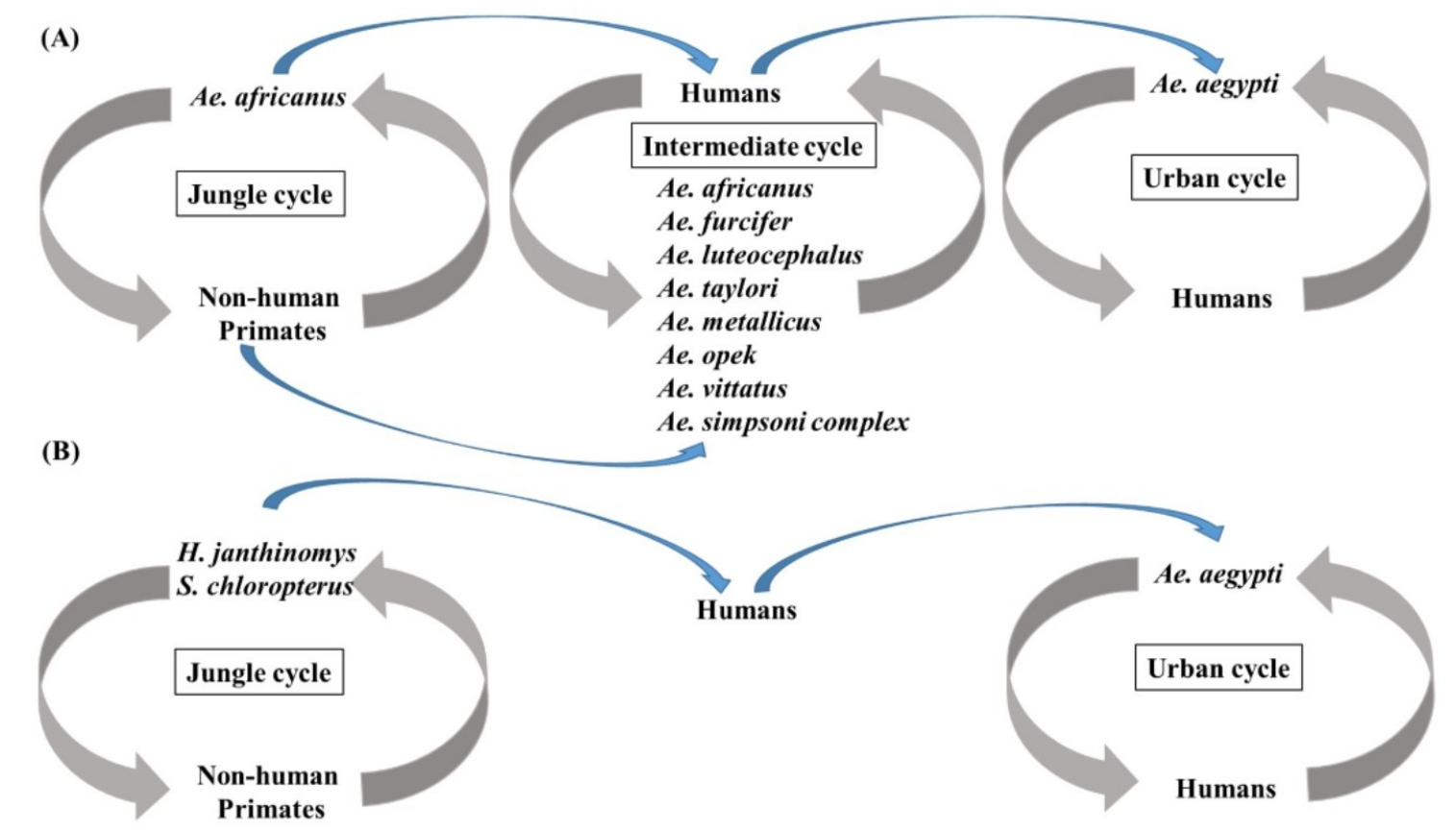

Figure 1. Transmission cycles of yellow fever virus (YFV) in Africa and South America. (A) Three transmission cycles support the transmission of YFV in Africa. In the jungle cycle, Ae. africanus is responsible for the transmission among non-human primates. In the intermediate cycle, human activities result in the biting of intermediate cycle vectors. In the urban transmission cycle, Ae. aegypti transmits YFV by feeding on viremic humans; (B) Two transmission cycles of YFV exist in South America. In the jungle cycle, $H$. janthinomys and S. chloropterus feed on infected non-human primates. In the urban cycle, Ae. aegypti are responsible for virus transmission.

Several studies reported the ability of Ae. aegypti to transmit YFV varied by geographical location [75,82,83], likely due to differences in vector genetics due to population isolation. Wallis et al. were able to select for YFV susceptibility by inbreeding isofemale lines of Ae. aegypti, and Miller and Mitchell selected for highly susceptible and highly refractory Ae. aegypti populations by selective breeding, confirming the role of vector genetics in virus susceptibility $[83,84]$. This could potentially have implications for control, if the vector genetic factors involved in virus infection and 
transmission are identified and used to engineer virus resistant mosquitoes. Another potential mechanism for control is the use of the endosymbiotic bacterium Wolbachia, as a $10^{4}$ times reduction in YFV copy number was observed in Ae. aegypti with the wMelPop strain compared to control mosquitoes. No difference was seen, however in YFV infection, dissemination, and replication in Ae. aegypti with the wMel strain of Wolbachia [85], so clearly this avenue requires additional research.

The role of viral genetics in transmission has also been studied extensively for YFV. The FNV virus derived from the French viscerotropic virus is also not transmitted by Ae. aegypti, and numerous sequence differences have been identified between the viruses although the contribution of specific amino acids is unknown [71,86]. An additional mutant produced by passage of YFV Asibi in HeLa cells was not transmitted by Ae. aegypti, and sequence comparisons revealed 10 amino acid differences from Asibi, including a mutation at position 95 in NS4B that was also present in 17D and FNV [87]. Similarly, infection of Ae. aegypti by the YFV 17D vaccine strain has been confirmed in multiple studies to be limited to the midgut [88-91]; the barrier to transmission has been found to be at the level of midgut escape, as 17D infects the salivary glands at a rate of $100 \%$ when the virus is inoculated into the thorax which bypasses the midgut $[88,89]$. This is most likely the result of a combination of 33 amino acid substitutions accumulated throughout the 17D genome during multiple passage of the wild-type Asibi parental strain. Using Asibi/17D chimeric infectious clones, McElroy et al. determined YFV dissemination within Ae. aegypti was under multigenic control and the cell receptor binding domain III of the envelope protein, NS2A, and NS4B likely play important roles in productive YFV-Ae. aegypti interactions based on chimera phenotypes in infected mosquitoes [89,92,93]. More recent work by Huang et al., found that a substitution at position E-380 modulated YFV infection but not dissemination in Ae. aegypti [94]. Additional characterization of the specific amino acids that play a role in YFV infection and dissemination in Ae. aegypti is needed.

\subsection{Dengue Virus Types $1-4$}

Dengue viruses are often considered the most important arboviruses worldwide causing an estimated 50-100 million infections per year and posing a threat to 2.5 billion people in tropical and subtropical regions. Although the majority of infections lead to self-limited febrile illness, the severe form of the disease can lead to life-threatening dengue hemorrhagic fever which has a mortality rate of $2.5 \%$ [95]. Urban transmission of all four serotypes of DENV is mainly mediated by Ae. aegypti and Ae. albopictus mosquitoes. Over the years, DENV has changed substantially. In the 1970s, only nine countries were considered endemic for DENV, currently there are more than 100 countries in Southeast Asia, Latin America, and the Western Pacific region affected by DENV [96]. Recently, local transmission of DENV has become a re-emerging threat to the United States with reports of local transmission in Florida and Houston, Texas [97,98]. Interestingly, local transmission of DENV in Houston has been shown to occur as early as 2003 [98]. Experimental infection and transmission of DENV in Ae. aegypti and Ae. albopictus have been extensively performed since the 1970s. Several studies have demonstrated competent vectors of DENV are present in various geographic locations [99-101]. Immunostaining of orally infected mosquitoes indicate replication and tropisms of DENV are similar to other flaviviruses [50,51,53,102,103]. The use of reverse genetics systems based on cDNA infectious clones to identify the genetic loci that determine the phenotypes of DENV in 
mosquitoes was an important advancement [104]. From these studies, there was evidence to suggest there are multiple molecular determinants located throughout the viral genome. The molecular hinge region between domain I and domain II in the envelope protein is likely to control the viral infectivity in Ae. aegypti [105]. The FG loop of domain III, which was initially determined to be a receptor-binding region, also contains the critical residues which determine viral infectivity [106,107]. In addition, the rational design of DENV vaccine candidates also identified several critical regions for viral infectivity. The deletion of the 3' untranslated region of DENV-4 resulted in the loss of viral infectivity and restricted replication in the midgut [108]. Recently, mutations in the DENV-2 2 '-O-methyltransferase were also shown to significantly reduce the infection and dissemination rates in orally challenged Ae. aegypti [109].

During the last two decades, significant progress has been made in the understanding of how mosquitoes respond to DENV infection and in the development of genetically modified mosquitoes that are resistant to DENV. One of the major advancements is the more detailed characterization of DENV infection in the arthropod vectors. The evidence demonstrated that innate immunity is an important physiological component to suppress the viral replication in mosquitoes. The expression of innate immunity-related genes in multiple signaling antiviral pathways such as the Toll, JAK-STAT and RNAi pathways can be up-regulated after the ingestion of viremic blood meals [110-113]. Interestingly, infection in mosquitoes also causes down-regulation of the immune deficiency (IMD) signaling pathway [114]. The suppression of the IMD pathway results in reduced production of antimicrobial peptides, which have been found to be critical for the control of gram-negative bacterial infections in mosquitoes and other insects [115]. Therefore, the immunomodulatory function of DENV can selectively inhibit the immunity that targets other pathogens invading the arthropod vectors such as bacteria. Such immunomodulation was subsequently found advantageous for viral infection as the presence of bacteria in the midgut can cause the activation of immune responses that suppress viral replication [116]. This finding, as well as transcriptome analyses in Ae. aegypti challenged by WNV and YFV, suggest that DENV and other flaviviruses actively suppress the expression of antiviral genes that limit viral replication [117]. Although transcriptome analyses of susceptible mosquito strains infected by DENV provided knowledge of how mosquito vectors respond to DENV infection, a critical gap in knowledge exists in the understanding of the variation in vector competence among different vector populations in nature. Transcriptome analyses on susceptible and refractory strains of Ae. aegypti suggests the expression of genes associated with specific pathways for metabolism, can contribute to the susceptibility and the refractoriness of Ae. aegypti to DENV within $24 \mathrm{~h}$ after engorgement of a viremic blood meal [118]. It is also clear the level of activated immune responses is involved in the susceptibility of Ae. aegypti to DENV [119]. Another factor required for the establishment of DENV infection in Ae. aegypti is V-ATPase which has been identified in RNAi screening and transcriptome analysis and tested with chemical inhibition assays in vivo [120-122]. Transcriptome analyses have expanded the understanding of mosquito responses to DENV infection. However, significant gaps still exist since the comparison of different serotypes and genotypes of DENV remains limited. With the evidence that different genotypes of DENV-2 show different phenotypes in mosquitoes, viral/vector characterization using reverse genetics systems and mosquitoes with different susceptibility is needed to determine the mechanisms that control the competence of arthropod vectors for DENV [46]. 
In spite of advancements in the development of vaccines and antiviral therapies, DENV control relies heavily on the reduction of competent vector populations in nature. Several innovative approaches have produced lines of mosquitoes that are refractory to DENV. Combining the viral genetic sequences and the RNAi pathway in mosquitoes, the susceptibility of transgenic Ae. aegypti was significantly reduced $[123,124]$. However, this approach was challenged by the potential loss of resistance in established colonies of transgenic mosquitoes [125]. In addition to engineering mosquitoes that are resistant to DENV, it is possible to engineer mosquitoes using the sterile insect technique (SIT) as another approach for vector control. SIT reduces the total population of competent vectors in disease endemic regions. Mating between a sterile male and a female will not lead to the production of offspring; therefore, by releasing a large number of sterile male insects that compete with normal males for mating, the total mosquito population is decreased. The remarkable success of SIT was first used in eliminating the New World screwworm and has also been applied to the development of genetically engineered Ae. aegypti that carry the lethal gene. The introduction of the lethal gene by releasing the transgenic males was expected to reduce the vector population in nature and provide an additional biological control strategy for Ae. aegypti [126]. Another method which was considered promising for vector control to reduce the transmission of DENV uses the obligatory intracellular Wolbachia to shorten the life span and reduce vector competence of Ae. aegypti [127]. Additionally, mating between Wolbachia-infected males with uninfected females causes embryonic lethality, which reduces the probability of producing large numbers of offspring which can further sustain the transmission of DENV and other arboviruses transmitted by Ae. aegypti. In summary, research on genetically modified Ae. aegypti and infection of Ae. aegypti by Wolbachia demonstrates the knowledge in virus-vector interactions can ultimately be applied to the development of biological control strategies for disease vectors. The development of biological control strategies for Ae. aegypti has resulted in the substantial advancement by offering alternative strategies for disease control and prevention. However, the importance of efficacious vaccines and antiviral therapies targeting DENV still should not be ignored.

The development of cDNA infectious clones and molecular genomic tools has improved our understanding of viral and host factors which play a role in the establishment of DENV infection of mosquitoes. The application of such knowledge has been applied for generating vaccine candidates that are biologically non-transmissible by susceptible vectors. Particularly important successes are the Chimerivax ${ }^{\circledR}$-DEN vaccines, which have been showed to impair infection, replication, and dissemination in field-collected Aedes spp. mosquitoes [128]. The trivalent Chimerivax ${ }^{\circledR}$-DEN vaccines show promise for the prevention and control of DENV infections. Ultimately, blocking DENV transmission will require a multi-disciplinary approach which targets immunologically naïve populations and competent vectors.

\subsection{Japanese Encephalitis Virus}

There are approximately three billion humans are at risk of contracting JEV via the bite of Culex mosquitoes, especially $C x$. tritaeniorhynchus and $C x$. vishnui which are associated with rice farming in Asia [129-131]. As shown in Figure 2, transmission of JEV is sustained between avian and swine species that act as amplification hosts and mosquitoes; humans and equine species are incidental hosts 
in this cycle. Serological surveillance has demonstrated transmission of JEV can be sustained between mosquitoes and swine species without initiating encephalitis outbreaks in humans [132,133]. According to World Health Organization data, there are 30,000-50,000 clinical cases reported annually with a $5 \%-30 \%$ case fatality rate [134]. Approximately $30 \%-50 \%$ of surviving patients experience permanent neuropsychiatric sequelae which creates significant challenges to long-term healthcare and results in severe economic loss. Therefore, several live-attenuated or inactivated vaccines have been developed and are now available for the control and prevention of JEV [63].

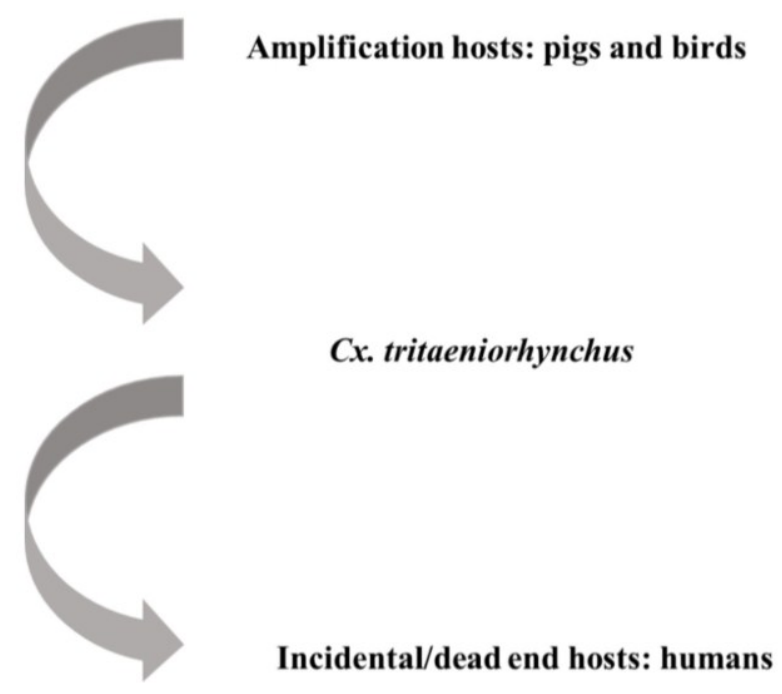

Figure 2. Transmission of Japanese encephalitis virus (JEV) is mainly maintained between viremic amplification hosts and Culex mosquitoes, especially Cx. tritaeniorhynchus. Infection of incidental hosts, such as humans, are unable to cause high titer viremia and sustain the transmission.

The primary vectors of JEV are Culex spp. mosquitoes in the Vishnui and Sitiens subgroups. In the Vishnui subgroup, Cx. tritaeniorhynchus and other mosquitoes are the competent vectors for transmission in Southeast Asia. JEV emergence has been reported in regions close to the Torres Strait in Australia since 1995 where JEV positive Cx. annulirostris and other members of the Sitiens subgroup have been found in nature [135-137]. Such epidemiological investigation on JEV-infected mosquitoes in Australia demonstrated the Culex spp. mosquitoes under the Sitiens subgroup, which utilize stagnant water as breeding sites, can also be vector species in addition to $C x$. tritaeniorhynchus and other Vishnui subgroup members that are mainly associated with rice farming [138]. The subsequent evaluation of susceptibility in Cx. sitiens collected from Malaysia suggested the same species present in Southeast Asia can also be infected by JEV [139]. In addition to the Culex spp. mosquitoes characterized as competent JEV vectors, it is noteworthy that JEV has a relatively wide range of susceptible vector species as several natural isolates of JEV were also reported in Anopheles and Aedes spp. mosquitoes [140-144]. Another interesting ecological observation was made through the analyses of feeding patterns which reflect the zoonotic nature of JEV. Analyses of feeding patterns of field-collected competent JEV vectors indicate $C x$. tritaeniorhynchus and $C x$. annulirostris have tendencies to feed on large mammals. Approximately $10 \%$ of the engorged mosquitoes contain blood 
from pigs. Pigs have been shown to develop a high titer JEV viremia able to cause infection of mosquitoes [145-147].

Transmission experiments, using artificial viremic blood meals or through feeding on viremic animals in the laboratory, have identified mechanisms of infection and dissemination of JEV in mosquitoes [53,103,148,149]. One factor that is important for viral transmission is the length of the extrinsic incubation period (EIP) in the mosquito which is determined by the viremic concentration ingested. JEV has been found to be very infectious to mosquitoes with less than 10 plaque forming units (p.f.u.) of virus required to infect competent vector species [150]. Viremic blood meals which were orally administered to $C x$. gelidus at $10^{3.5}-10^{4.8}$ p.f.u. $/ \mathrm{mL}$ were found to shorten EIP to 6-10 days in contrast to 11-15 days among the mosquitoes exposed to blood meals at $10^{1.5}-10^{3.4}$ p.f.u. $/ \mathrm{mL}$ [149]. During the EIP, the propagation of viruses led to the escape of progeny virions from the midgut and to secondary tissues as visualized by immunofluorescence staining of infected mosquito tissues [53,103]. A consequence of viral replication in the salivary glands is the accumulation of mature virions in the intracytoplasmic region of cells that results in the release of infectious virions into the apical cavity for transmission [148]. In addition to the ingestion of viremic blood meals, the infection of adult mosquitoes can be the consequence of transovarial transmission, which has also been reported as a strategy that allows the maintenance of several other arboviruses in nature [151,152].

Similar to other arboviruses, JEV genetics play a critical role in infection and dissemination in mosquitoes. The attenuated JE 2-8 strain of JEV derived from the serial passage of the virulent SA14 strain in vitro resulted in the accumulation of mutations and the loss of infectivity and disseminating capacity in Cx. tritaeniorhynchus [153]. In the same study, propagation of the SA14 strain constantly led to the higher titers in either intrathoracically inoculated or orally challenged mosquitoes. However, individual genetic mutations resulting from serial passage in vitro that are responsible for the phenotypic changes have not been identified. Additionally, it is unknown if the live-attenuated SA14-14-2 vaccine strain, which was derived from the same parental virulent strain through the serial passages in different cell types, is biologically non-transmissible by mosquitoes. In a study evaluating the ability of the chimeric JEV vaccine to be transmitted by viremic vaccinees found the live-attenuated chimeric JEV vaccine based on YFV backbone did not infect or disseminate in Cx. annulirostris, Cx. gelidusm, and Ae. vigilax [154]. However, it is unclear whether the attenuation is caused by the specific genetic mutations or the chimerization of JEV and YFV genetic materials. As previously reported, the chimerization of genetic materials between two different flaviviruses often resulted in attenuation [89,155]. In contrast to the success in utilizing infectious clones to study the genetic determinants of YFV infection and dissemination in Ae. aegypti, the development of JEV infectious clones has been challenging because the propagation of the full-length cDNA genomes in bacterial plasmids often results in rapid mutations [156]. Therefore, the development of cDNA infectious platforms of JEV was either based on multi-plasmid platforms or optimized by the introduction of intron sequences to reduce the toxicity to bacterial hosts $[156,157]$. Recently, there have been several studies using either low-copy plasmids or bacterial artificial chromosomes in order to maintain the stability of viral genomic sequences in the plasmids propagated in E. coli $[158,159]$. An additional alternative approach has been proposed and found feasible by creating silent mutations by substituting the nucleotide sequences of viral cDNA that resemble the $E$. coli promoter sequences without changing the amino acid sequences [160]. In order to identify the genetic determinants for 
viral infectivity and disseminating capacity in mosquitoes, an optimized molecular virology platform is needed for the subsequent manipulations of viral genomes. As described above, the major difficulty in developing JEV reverse genetics systems is due to difficulties associated with genetic stability. Without a reverse genetics system that assures the fidelity of cDNA propagation, the evaluation of specific genetic mutations can be technically infeasible. Characterization of viral genetic factors that govern the infection and dissemination of JEV in mosquitoes is critical for the vaccination with live-attenuated vaccines because previous studies have shown infection of arthropods by live-attenuated arbovirus vaccines can potentially contribute to further transmission [161].

Previous studies suggest JEV introduction into new geographic areas is possible where there are competent mosquitoes and susceptible vertebrate hosts. The introduction of JEV into Australia and WNV into the United States exemplify how rapidly JEV-serocomplex flaviviruses can establish in geographic regions where the competent vectors are present and the vertebrate hosts are immunologically naïve. Based on a series of experiments performed with colonized American mosquitoes exposed to JEV, several species have been found susceptible after the engorgement of viremic blood from infected mice [162]. Among the vector species tested for JEV in the study, $C x$. pipiens, Cx. quinquefasciatus and Cx. tarsalis where found to be competent for JEV and therefore could potentially transmit this virus in the New World. These mosquitoes are also considered competent vectors for WNV, as discussed below. The large number of farmed pigs combined with potential wild mammal and avian hosts could serve as amplification hosts for JEV after an introduction into the US. In the absence of a comprehensive assessment of vertebrate host and mosquito susceptibility, it is difficult to estimate the likelihood that JEV could potentially become endemic in the US after an introduction.

\subsection{West Nile Virus}

Another medically important flavivirus in the JEV serocomplex is WNV, first isolated from the blood of a febrile woman in the West Nile district of Uganda in 1937 [163]. It is the most widely distributed of the flaviviruses, with strains from one of the two WNV lineages distributed throughout Southeast Asia, southern and Eastern Europe, Australia, and recently, the Americas [164-167]. Typically arboviruses infect a limited number of vectors with transmission cycles often involving just two or three key species. WNV is unusual since it has been reported to be infectious to more than 60 species of vectors. The establishment of WNV in North America after its introduction in 1999 has demonstrated how readily WNV can adapt and establish transmission cycles in different ecological niches with susceptible vertebrate hosts and competent vector species [168-170]. In the Americas, naïve avian populations which lack herd immunity against WNV act as the primary amplification hosts in the transmission cycle [171]. Culex spp. mosquitoes are the primary vector in North America and also serve as a bridge vector. Due to the relatively large number of olfactory receptors in Culex spp. mosquitoes, they often feed on both viremic avian amplifying hosts and incidental human or equine species [172]. Viremic transmission of arboviruses by mosquitoes requires vertebrate hosts that develop high viremic titers. However, WNV transmission has also been found to occur following the simultaneous feeding of infected and uninfected arthropods on the same animal. Detection of virus is difficult during the initial feeding of an infected mosquito on a vertebrate host; therefore this mode of 
transmission has been termed "non-viremic transmission". However, it might more accurately be termed non-replicative transmission because it involves transmission of virus between arthropods without the requirement of host infection and virus replication in the vertebrate [173-175]. Transmission takes place primarily due to a transient secretion of a high concentration of virions from infected mosquitoes. The experimental evidence supports such a hypothesis, as the spatial and temporal proximity of feeding between the infected donor mosquitoes and the uninfected recipient mosquitoes are critical factors for the transmission to occur [176]. These findings challenge the established concept that mosquitoes feeding on dead-end hosts cannot contribute to the transmission of WNV.

Several new genotypes have been identified since the establishment of WNV in North America, some of which have been well-characterized. The first genotype to be identified in North America was found in New York in 1999 (NY99). The NY99 genotype was isolated between 1999 and 2003 and has subsequently been considered extinct, possibly due to the displacement by other genotypes [38]. Four additional genotypes have since been identified in North America: NA/WN02, SW/WN03, MW/WN06, and the now extinct southeastern Coastal Texas. Using a method to determine the relative susceptibility of mosquitoes to infection with various genotypes, variation in the oral infectious dose $50 \%\left(\mathrm{OID}_{50}\right)$ was found among different $\mathrm{WNV}$ genotypes which were orally fed to Cx. quinquefasciatus [177]. Between 2001 and 2004, the displacement of the NY99 genotype with the NA/WN02 genotype demonstrated mutations in the E protein can potentially increase the epidemic potential by shortening the incubation period. Initial evidence suggested the NA/WN02 genotype can be more infectious, i.e., lower required infectious dose, based on its higher infection rate in Cx. pipiens than the NY99 genotype [44]. However, the NA/WN02 OID50 for Cx. quinquefasciatus has no demonstrable difference from that of the NY99 genotype, a selective advantage also potentially exists in the dissemination and transmission process [177]. This hypothesis was later validated by per os challenge of $C x$. tarsalis, the predominant enzootic and bridging vector in the western part of United States, with the NA/WN02 genotype, which had a shorter incubation period than infection with the NY99 genotype [45]. Such a difference was attributed to the E-V159A mutation. Genetic characterizations also demonstrated the advantageous role of the E-V159A mutation, which is conserved among all currently circulating genotypes. The southeastern Coastal Texas genotype, which does not contain the E-V159A mutation, was transiently circulated before 2002 [40]. In addition to phenotypic effects of changes in the $\mathrm{E}$ gene, attenuation of WNV can be achieved by manipulating the NS2, NS4B and NS5 genes [178-180]. These studies used reverse genetics systems to introduce point mutations to WNV genomes in order to functionally characterize the nonstructural proteins and ultimately lead to attenuated strains of WNV. Originally identified in JEV and further proposed as a potential attenuation mechanism for the SA14-14-2 vaccine strain, the programmed ribosome frame shift occurs in the $5^{\prime}$ terminus of the NS2 gene and results in the production of an additional nonstructural protein NS1' in several JEV-serocomplex flaviviruses including WNV [181-183]. Although the functions of NS1' proteins have not been completely understood, the abolishment of the production of NS1' has been demonstrated to impair the replication and dissemination of WNV in Cx. annulirostris [184]. Mutational analyses of the WNV NS4B protein demonstrated the $N$-terminal and the central hydrophobic regions contain the genetic determinants for virulence in mice [178,179], but such mutations in NS4B, the P38G and T116I substitutions, resulted in the enhancement of viral 
dissemination and transmission in Cx. tarsalis [185]. Evaluation of critical residues in the rNTP-binding region of WNV NS5 protein showed deliberate stabilization of the local secondary structures by increasing the molecular interactions through genetic mutations can result in the loss of viral fitness including the lower level of viral replication in $C x$. pipiens [180]. Characterization of WNV genotypes found selective advantages such as higher infectivity and shorter extrinsic incubation periods in mosquitoes are due to mutations in the E protein. Molecular virological manipulation of WNV demonstrated several genetic loci in the non-structural genes that can lead to the attenuation of WNV in vivo; especially the abolishment in the production of NS1' protein. However, the mutations in the NS4B protein, which were reported to reduce the virulence in mammalian hosts and considered attenuation determinants, showed the opposite impact by increasing the viral fitness of WNV in specific infected mosquito species.

For all genotypes of WNV, maintenance of viral populations through winter climatic conditions is an important ecological question because of the lack of active transmission in the winter. It seems reasonable to speculate WNV may share certain overwintering mechanisms with closely related JEV such as transovarial transmission and persistent infection of diapausing mosquitoes. WNV viral RNA can be detected in hibernating Culex spp. mosquitoes in nature, so persistent infection has been identified as a potential mechanism for viral maintenance during cold periods [186]. Although prolonged WNV infection during overwintering can lead to cytopathic effects in mosquitoes, the transmission capacity of persistently infected mosquitoes is unaffected $[187,188]$. There are a large number of competent vector species for WNV, so it is likely virus overwintering occurs in multiple species. For example, it has been suggested species such as $C x$. restuans, whose adult populations peak in the spring, serve as the early amplification host for WNV prior to the emergence of other vector species [189]. WNV has been detected in ovaries and neighboring tissues [52] and WNV can be maintained through transovarial transmission in $C x$. pipiens, Cx. quinquefasciatus, Cx. tarsalis and Cx. vishnui $[190,191]$.

Although infection of WNV has been known to occur in various Culex spp. mosquitoes, the detailed characterization of how mosquitoes develop physiological and antiviral responses to WNV infection has only recently been studied since the elucidation of the Cx. quinquefasciatus genomic sequence [172]. RNAi antiviral responses described in other arboviruses were found to be important for limiting infection of WNV and subsequently inducing diversification of viral genetics [192,193]. Additional immune signaling pathways can potentially be induced including Toll, Imd, and JAK/STAT signaling pathways [194]. The most direct evidence was derived from the observation that the secreted form of Vago protein is critical for the induction of JAK/STAT signaling and restricting WNV replication in vitro [195]. Experiments using Ae. aegypti as a model found WNV infection leads to the down regulation of genes which limit the viral replication [117]. This observation is consistent with the immunomodulation caused by DENV in mosquitoes indicating WNV infection may also actively suppress the antiviral responses developed by mosquitoes.

The study of WNV in mosquitoes has been further extended to the characterization of interactions among viruses, mosquitoes, and vertebrate hosts. An interesting discovery resulting from studies designed to characterize interactions between WNV and mosquitoes is the potentiation of vertebrate infection caused by the salivary component of mosquitoes [196]. The presence of salivary components enhance the disease progress of WNV in the murine model and mosquito feeding increased mortality 
rates among infected mice [197]. Based on these and other studies, the potentiation of infection is due to the modulation of host immune responses, especially suppressing the antiviral $\mathrm{T}_{\mathrm{H}} 1$ immune response, and other factors, for example migration of susceptible cell types to the inoculation site [198].

Observations from the relatively short time since the introduction of WNV into the Americas and its continued spread suggests further genetic changes may occur in response to additional selection pressure. Because WNV is principally transmitted by multiple Culex spp. mosquitoes, it remains controversial if specific genetic substitutions that favor the establishment of infection in a particular species also have a similar effect on WNV infection in other mosquitoes [199]. Previous studies predominantly focused on evaluating the susceptibility and the capacity of WNV transmission by particular species; future investigations of the temporal and spatial patterns of viral infection of WNV vectors may characterize viral or vector genetic factors that determine ecological selective advantage or relative disadvantage of specific genotypes compared to others under certain conditions.

\section{Conclusions}

There are still significant gaps in the fundamental knowledge related to many arboviruses. Despite physical geographic boundaries, the distribution of specific flaviviruses has continuously changed throughout human history. It is intuitive to assume the presence of competent vectors and susceptible hosts in suitable climatic conditions are sufficient for the introduction of flaviviruses into areas where they are originally absent. For example, YFV was introduced and readily established its transmission in the New World because of the slave trade [19]. More recently, the eastward spread of JEV which successfully crossed the Torres strait and crossed the hypothetical Wallace line, that separates Southeast Asia from Australia, in late 20th century [136]. Similarly, despite the large distance from endemic areas, there have been abrupt and explosive epidemics of WNV in North America since 1999 [129]. In the latter two examples, the establishment of transmission cycles was a consequence of flaviviruses vectored by mosquito species which are different from the original endemic regions. Therefore, it is immediately apparent that the knowledge in flavivirus-mosquito interactions is critical for the prediction of the changing epidemiology and the epidemic potential of mosquito-borne flaviviruses. Clearer understanding of the vectors and vertebrate host interactions may enable predictions of how these viruses can spread from one region to another in the future and ultimately be applied to the development of more efficient disease control strategies.

\section{Author Contributions}

Yan-Jang S. Huang, Stephen Higgs, Kate McElroy Horne, and Dana L. Vanlandingham contributed to the content and editing of this article.

\section{Conflicts of Interest}

The authors declare no conflict of interest. 


\section{References and Notes}

1. Lindenbach, B.D.; Rice, C.M. Molecular biology of flaviviruses. Adv. Virus Res. 2003, 59, 23-61.

2. Durbin, A.P.; Mayer, S.V.; Rossi, S.L.; Amaya-Larios, I.Y.; Ramos-Castaneda, J.; Eong Ooi, E.; Jane Cardosa, M.; Munoz-Jordan, J.L.; Tesh, R.B.; Messer, W.B.; et al. Emergence potential of sylvatic dengue virus type 4 in the urban transmission cycle is restrained by vaccination and homotypic immunity. Virology 2013, 439, 34-41.

3. Petersen, L.R.; Marfin, A.A. Shifting epidemiology of Flaviviridae. J. Travel Med. 2005, 12 (Suppl. 1), S3-S11.

4. Bowen, R.A.; Nemeth, N.M. Experimental infections with West Nile virus. Curr. Opin. Infect. Dis. 2007, 20, 293-297.

5. Barrett, A.D.; Higgs, S. Yellow fever: A disease that has yet to be conquered. Ann. Rev. Entomol. 2007, 52, 209-229.

6. Barrett, A.D.; Monath, T.P. Epidemiology and ecology of yellow fever virus. Adv. Virus Res. 2003, 61, 291-315.

7. Gubler, D.J. The changing epidemiology of yellow fever and dengue, 1900 to 2003: Full circle? Comp. Immunol. Microbiol. Infect. Dis. 2004, 27, 319-330.

8. Vasilakis, N.; Deardorff, E.R.; Kenney, J.L.; Rossi, S.L.; Hanley, K.A.; Weaver, S.C. Mosquitoes put the brake on arbovirus evolution: Experimental evolution reveals slower mutation accumulation in mosquito than vertebrate cells. PLoS Pathog. 2009, 5, e1000467.

9. Carrington, C.V.; Auguste, A.J. Evolutionary and ecological factors underlying the tempo and distribution of yellow fever virus activity. Infect. Genet. Evol. 2013, 13, 198-210.

10. Coffey, L.L.; Forrester, N.; Tsetsarkin, K.; Vasilakis, N.; Weaver, S.C. Factors shaping the adaptive landscape for arboviruses: Implications for the emergence of disease. Future Microbiol. 2013, 8, 155-176.

11. Gould, E.A.; de Lamballerie, X.; Zanotto, P.M.; Holmes, E.C. Evolution, epidemiology, and dispersal of flaviviruses revealed by molecular phylogenies. Adv. Virus Res. 2001, 57, 71-103.

12. Gould, E.A.; de Lamballerie, X.; Zanotto, P.M.; Holmes, E.C. Origins, evolution, and vector/host coadaptations within the genus Flavivirus. Adv. Virus Res. 2003, 59, 277-314.

13. Kuno, G.; Chang, G.J. Biological transmission of arboviruses: Re-examination of and new insights into components, mechanisms, and unique traits as well as their evolutionary trends. Clin. Microbiol. Rev. 2005, 18, 608-637.

14. Kuno, G.; Chang, G.J.; Tsuchiya, K.R.; Karabatsos, N.; Cropp, C.B. Phylogeny of the genus Flavivirus. J. Virol. 1998, 72, 73-83.

15. Mattingly, P.F. II. Ecological aspects of the evolution of mosquito-borne virus diseases. Trans. R. Soc. Trop. Med. Hyg. 1960, 54, 97-112.

16. Cook, S.; Moureau, G.; Kitchen, A.; Gould, E.A.; de Lamballerie, X.; Holmes, E.C.; Harbach, R.E. Molecular evolution of the insect-specific flaviviruses. J. Gen. Virol. 2012, 93, 223-234. 
17. Huhtamo, E.; Cook, S.; Moureau, G.; Uzcategui, N.Y.; Sironen, T.; Kuivanen, S.; Putkuri, N.; Kurkela, S.; Harbach, R.E.; Firth, A.E.; et al. Novel flaviviruses from mosquitoes: Mosquito-specific evolutionary lineages within the phylogenetic group of mosquito-borne flaviviruses. Virology 2014, 464-465, 320-329.

18. Mutebi, J.P.; Barrett, A.D. The epidemiology of yellow fever in Africa. Microb. Infect. Inst. Pasteur 2002, 4, 1459-1468.

19. Bryant, J.E.; Holmes, E.C.; Barrett, A.D. Out of Africa: A molecular perspective on the introduction of yellow fever virus into the Americas. PLoS Pathog. 2007, 3, e75.

20. Stock, N.K.; Boschetti, N.; Herzog, C.; Appelhans, M.S.; Niedrig, M. The phylogeny of yellow fever virus 17D vaccines. Vaccine 2012, 30, 989-994.

21. Holmes, E.C.; Twiddy, S.S. The origin, emergence and evolutionary genetics of dengue virus. Infect. Genet. Evol. 2003, 3, 19-28.

22. Rico-Hesse, R. Molecular evolution and distribution of dengue viruses type 1 and 2 in nature. Virology 1990, 174, 479-493.

23. Myat Thu, H.; Lowry, K.; Jiang, L.; Hlaing, T.; Holmes, E.C.; Aaskov, J. Lineage extinction and replacement in dengue type 1 virus populations are due to stochastic events rather than to natural selection. Virology 2005, 336, 163-172.

24. Raghwani, J.; Rambaut, A.; Holmes, E.C.; Hang, V.T.; Hien, T.T.; Farrar, J.; Wills, B.; Lennon, N.J.; Birren, B.W.; Henn, M.R.; et al. Endemic dengue associated with the co-circulation of multiple viral lineages and localized density-dependent transmission. PLoS Pathog. 2011, 7, e1002064.

25. Aviles, G.; Meissner, J.; Mantovani, R.; St Jeor, S. Complete coding sequences of dengue-1 viruses from Paraguay and Argentina. Virus Res. 2003, 98, 75-82.

26. Twiddy, S.S.; Farrar, J.J.; Vinh Chau, N.; Wills, B.; Gould, E.A.; Gritsun, T.; Lloyd, G.; Holmes, E.C. Phylogenetic relationships and differential selection pressures among genotypes of dengue-2 virus. Virology 2002, 298, 63-72.

27. King, C.C.; Chao, D.Y.; Chien, L.J.; Chang, G.J.; Lin, T.H.; Wu, Y.C.; Huang, J.H. Comparative analysis of full genomic sequences among different genotypes of dengue virus type 3. Virol. J. 2008, 5, 63 .

28. Nogueira, M.B.; Stella, V.; Bordignon, J.; Batista, W.C.; Borba, L.; Silva, L.H.; Hoffmann, F.G.; Probst, C.M.; Santos, C.N. Evidence for the co-circulation of dengue virus type 3 genotypes III and $\mathrm{V}$ in the northern region of Brazil during the 2002-2004 epidemics. Mem. Inst. Oswaldo Cruz 2008, 103, 483-488.

29. Lanciotti, R.S.; Gubler, D.J.; Trent, D.W. Molecular evolution and phylogeny of dengue-4 viruses. J. Gen. Virol. 1997, 78 Pt 9, 2279-2284.

30. Klungthong, C.; Zhang, C.; Mammen, M.P., Jr.; Ubol, S.; Holmes, E.C. The molecular epidemiology of dengue virus serotype 4 in Bangkok, Thailand. Virology 2004, 329, 168-179.

31. AbuBakar, S.; Wong, P.F.; Chan, Y.F. Emergence of dengue virus type 4 genotype IIA in Malaysia. J. Gen. Virol. 2002, 83, 2437-2442.

32. Villabona-Arenas, C.J.; Zanotto, P.M. Evolutionary history of dengue virus type 4: Insights into genotype phylodynamics. Infect. Genet. Evol. J. Mol. Epidemiol. Evol. Genet. Infect. Dis. 2011, 11, 878-885. 
33. Solomon, T.; Ni, H.; Beasley, D.W.; Ekkelenkamp, M.; Cardosa, M.J.; Barrett, A.D. Origin and evolution of Japanese encephalitis virus in Southeast Asia. J. Virol. 2003, 77, 3091-3098.

34. Takhampunya, R.; Kim, H.C.; Tippayachai, B.; Kengluecha, A.; Klein, T.A.; Lee, W.J.; Grieco, J.; Evans, B.P. Emergence of Japanese encephalitis virus genotype V in the Republic of Korea. Virol. J. 2011, 8, 449.

35. Williams, D.T.; Wang, L.F.; Daniels, P.W.; Mackenzie, J.S. Molecular characterization of the first Australian isolate of Japanese encephalitis virus, the FU strain. J. Gen. Virol. 2000, 81, 2471-2480.

36. Pyke, A.T.; Williams, D.T.; Nisbet, D.J.; van den Hurk, A.F.; Taylor, C.T.; Johansen, C.A.; Macdonald, J.; Hall, R.A.; Simmons, R.J.; Mason, R.J.; et al. The appearance of a second genotype of Japanese encephalitis virus in the Australasian region. Am. J. Trop. Med. Hyg. 2001, $65,747-753$.

37. Schuh, A.J.; Ward, M.J.; Leigh Brown, A.J.; Barrett, A.D. Dynamics of the emergence and establishment of a newly dominant genotype of Japanese encephalitis virus throughout Asia. J. Virol. 2014, 88, 4522-4532.

38. Mann, B.R.; McMullen, A.R.; Swetnam, D.M.; Barrett, A.D. Molecular epidemiology and evolution of West Nile virus in North America. Int. J. Environ. Res. Public Health 2013, 10, 5111-5129.

39. May, F.J.; Davis, C.T.; Tesh, R.B.; Barrett, A.D. Phylogeography of West Nile virus: From the cradle of evolution in Africa to Eurasia, Australia, and the Americas. J. Virol. 2011, 85, 2964-2974.

40. Davis, C.T.; Beasley, D.W.; Guzman, H.; Siirin, M.; Parsons, R.E.; Tesh, R.B.; Barrett, A.D. Emergence of attenuated West Nile virus variants in Texas, 2003. Virology 2004, 330, 342-350.

41. Beasley, D.W.; Davis, C.T.; Guzman, H.; Vanlandingham, D.L.; Travassos da Rosa, A.P.; Parsons, R.E.; Higgs, S.; Tesh, R.B.; Barrett, A.D. Limited evolution of West Nile virus has occurred during its southwesterly spread in the United States. Virology 2003, 309, 190-195.

42. Davis, C.T.; Ebel, G.D.; Lanciotti, R.S.; Brault, A.C.; Guzman, H.; Siirin, M.; Lambert, A.; Parsons, R.E.; Beasley, D.W.; Novak, R.J.; et al. Phylogenetic analysis of North American West Nile virus isolates, 2001-2004: Evidence for the emergence of a dominant genotype. Virology 2005, 342, 252-265.

43. Cologna, R.; Armstrong, P.M.; Rico-Hesse, R. Selection for virulent dengue viruses occurs in humans and mosquitoes. J. Virol. 2005, 79, 853-859.

44. Ebel, G.D.; Carricaburu, J.; Young, D.; Bernard, K.A.; Kramer, L.D. Genetic and phenotypic variation of West Nile virus in New York, 2000-2003. Am. J. Trop. Med. Hyg. 2004, 71, 493-500.

45. Moudy, R.M.; Meola, M.A.; Morin, L.L.; Ebel, G.D.; Kramer, L.D. A newly emergent genotype of West Nile virus is transmitted earlier and more efficiently by Culex mosquitoes. Am. J. Trop. Med. Hyg. 2007, 77, 365-370.

46. Armstrong, P.M.; Rico-Hesse, R. Efficiency of dengue serotype 2 virus strains to infect and disseminate in Aedes aegypti. Am. J. Trop. Med. Hyg. 2003, 68, 539-544.

47. Rosen, L. Further observations on the mechanism of vertical transmission of flaviviruses by Aedes mosquitoes. Am. J. Trop. Med. Hyg. 1988, 39, 123-126. 
48. Khin, M.M.; Than, K.A. Transovarial transmission of dengue 2 virus by Aedes aegypti in nature. Am. J. Trop. Med. Hyg. 1983, 32, 590-594.

49. Mourya, D.T.; Mishra, A.C. Antigen distribution pattern of Japanese encephalitis virus in Culex tritaeniorhynchus, C. vishnui \& C. pseudovishnui. Indian J. Med. Res. 2000, 111, 157-161.

50. McElroy, K.L.; Girard, Y.A.; McGee, C.E.; Tsetsarkin, K.A.; Vanlandingham, D.L.; Higgs, S. Characterization of the antigen distribution and tissue tropisms of three phenotypically distinct yellow fever virus variants in orally infected Aedes aegypti mosquitoes. Vector Borne Zoonotic Dis. 2008, 8, 675-687.

51. Linthicum, K.J.; Platt, K.; Myint, K.S.; Lerdthusnee, K.; Innis, B.L.; Vaughn, D.W. Dengue 3 virus distribution in the mosquito Aedes aegypti: An immunocytochemical study. Med. Vet. Entomol. 1996, 10, 87-92.

52. Girard, Y.A.; Klingler, K.A.; Higgs, S. West Nile virus dissemination and tissue tropisms in orally infected Culex pipiens quinquefasciatus. Vector Borne Zoonotic Dis. 2004, 4, 109-122.

53. Doi, R.; Shirasaki, A.; Sasa, M. The mode of development of Japanese encephalitis virus in the mosquito Culex tritaeniorhynchus summorosus as observed by the fluorescent antibody technique. Jpn. J. Exp. Med. 1967, 37, 227-238.

54. Diallo, M.; Sall, A.A.; Moncayo, A.C.; Ba, Y.; Fernandez, Z.; Ortiz, D.; Coffey, L.L.; Mathiot, C.; Tesh, R.B.; Weaver, S.C. Potential role of sylvatic and domestic African mosquito species in dengue emergence. Am. J. Trop. Med. Hyg. 2005, 73, 445-449.

55. Romano, A.P.; Costa, Z.G.; Ramos, D.G.; Andrade, M.A.; Jayme Vde, S.; Almeida, M.A.; Vettorello, K.C.; Mascheretti, M.; Flannery, B. Yellow fever outbreaks in unvaccinated populations, Brazil, 2008-2009. PLoS Negl. Trop. Dis. 2014, 8, e2740.

56. World Health Organization. The yellow fever situation in Africa and South America in 2004. Wkly. Epidemiol. Rec. 2005, 80, 250-256.

57. World Health Organization. Yellow fever situation in Africa and South America, 2005. Wkly. Epidemiol. Rec. 2006, 81, 317-324.

58. World Health Organization. Yellow fever in Africa and South America, 2006. Wkly. Epidemiol. Rec. 2008, 83, 60-76.

59. World Health Organization. Yellow fever in Africa and South America, 2007. Wkly. Epidemiol. Rec. 2009, 84, 97-104.

60. World Health Organization. Yellow fever in Africa and Central and South America, 2008-2009. Wkly. Epidemiol. Rec. 2011, 86, 25-36.

61. World Health Organization. Yellow fever in Africa and South America, 2011-2012. Wkly. Epidemiol. Rec. 2013, 88, 285-296.

62. World Health Organization. Yellow fever in Africa and South America, 2013. Wkly. Epidemiol. Rec. 2014, 89, 297-306.

63. Halstead, S.B.; Thomas, S.J. New vaccines for Japanese encephalitis. Curr. Infect. Dis. Rep. 2010, 12, 174-180.

64. Rosen, L. The natural history of Japanese encephalitis virus. Ann. Rev. Microbiol. 1986, 40, 395-414. 
65. Go, Y.Y.; Balasuriya, U.B.; Lee, C.K. Zoonotic encephalitides caused by arboviruses: Transmission and epidemiology of alphaviruses and flaviviruses. Clin. Exp. Vaccine Res. 2014, 3, 58-77.

66. Blitvich, B.J. Transmission dynamics and changing epidemiology of West Nile virus. Anim. Health Res. Rev. Conf. Res. Work. Anim. Dis. 2008, 9, 71-86.

67. Finlay, C.J. The mosquito hypothetically considered as the agent of transmission of yellow fever. 1881. Mil. Med. 2001, 166 (9 Suppl.), 6-10.

68. Reed, W.; Carroll, J.; Agramonte, A. Experimental yellow fever. 1901. Mil. Med. 2001, 166, 55-60.

69. Reed, W.; Carroll, J.; Agramonte, A. The etiology of yellow fever: An additional note, 1901. Mil. Med. 2001, 166, 44-53.

70. Reed, W.; Carroll, J.; Agramonte, A.; Lazear, J.W. The etiology of yellow fever-A preliminary note. Public Health Pap. Rep. 1900, 26, 37-53.

71. Barrett, A.D. Yellow fever vaccines. Biol. J. Int. Assoc. Biol. Stand. 1997, 25, 17-25.

72. Strode, G.K.; Rockefeller Foundation. International Health Division. In Yellow Fever, 1st ed.; McGraw-Hill: New York, NY, USA, 1951; p. 710.

73. Tomori, O. Yellow fever: The recurring plague. Crit. Rev. Clin. Lab. Sci. 2004, 41, 391-427.

74. Monath, T.P. Yellow fever: An update. Lancet Infect. Dis. 2001, 1, 11-20.

75. Tabachnick, W.J.; Wallis, G.P.; Aitken, T.H.; Miller, B.R.; Amato, G.D.; Lorenz, L.; Powell, J.R.; Beaty, B.J. Oral infection of Aedes aegypti with yellow fever virus: Geographic variation and genetic considerations. Am. J. Trop. Med. Hyg. 1985, 34, 1219-1224.

76. van den Hurk, A.F.; McElroy, K.; Pyke, A.T.; McGee, C.E.; Hall-Mendelin, S.; Day, A.; Ryan, P.A.; Ritchie, S.A.; Vanlandingham, D.L.; Higgs, S. Vector competence of Australian mosquitoes for yellow fever virus. Am. J. Trop. Med. Hyg. 2011, 85, 446-451.

77. Bauer, J.H.; Hudson, N.P. The incubation period of yellow fever in the mosquito. J. Exp. Med. 1928, 48, 147-153.

78. Aitken, T.H.; Tesh, R.B.; Beaty, B.J.; Rosen, L. Transovarial transmission of yellow fever virus by mosquitoes (Aedes aegypti). Am. J. Trop. Med. Hyg. 1979, 28, 119-121.

79. Beaty, B.J.; Tesh, R.B.; Aitken, T.H. Transovarial transmission of yellow fever virus in Stegomyia mosquitoes. Am. J. Trop. Med. Hyg. 1980, 29, 125-132.

80. Philip, C.B. Transmission of yellow fever virus by aged Aedes aegypti and comments on some other mosquitovirus relationships. Am. J. Trop. Med. Hyg. 1962, 11, 697-701.

81. Miller, B.R.; Mitchell, C.J.; Ballinger, M.E. Replication, tissue tropisms and transmission of yellow fever virus in Aedes albopictus. Trans. R. Soc. Trop. Med. Hyg. 1989, 83, 252-255.

82. Aitken, T.H.; Downs, W.G.; Shope, R.E. Aedes aegypti strain fitness for yellow fever virus transmission. Am. J. Trop. Med. Hyg. 1977, 26, 985-989.

83. Wallis, G.P.; Aitken, T.H.; Beaty, B.J.; Lorenz, L.; Amato, G.D.; Tabachnick, W.J. Selection for susceptibility and refractoriness of Aedes aegypti to oral infection with yellow fever virus. Am. J. Trop. Med. Hyg. 1985, 34, 1225-1231.

84. Miller, B.R.; Mitchell, C.J. Genetic selection of a flavivirus-refractory strain of the yellow fever mosquito Aedes aegypti. Am. J. Trop. Med. Hyg. 1991, 45, 399-407. 
85. Van den Hurk, A.F.; Hall-Mendelin, S.; Pyke, A.T.; Frentiu, F.D.; McElroy, K.; Day, A.; Higgs, S.; O’Neill, S.L. Impact of Wolbachia on infection with chikungunya and yellow fever viruses in the mosquito vector Aedes aegypti. PLoS Negl. Trop. Dis. 2012, 6, e1892.

86. Wang, E.; Ryman, K.D.; Jennings, A.D.; Wood, D.J.; Taffs, F.; Minor, P.D.; Sanders, P.G.; Barrett, A.D. Comparison of the genomes of the wild-type French viscerotropic strain of yellow fever virus with its vaccine derivative French neurotropic vaccine. J. Gen. Virol. 1995, 76 Pt 11, 2749-2755.

87. Dunster, L.M.; Wang, H.; Ryman, K.D.; Miller, B.R.; Watowich, S.J.; Minor, P.D.; Barrett, A.D. Molecular and biological changes associated with HeLa cell attenuation of wild-type yellow fever virus. Virology 1999, 261, 309-318.

88. Jennings, A.D.; Gibson, C.A.; Miller, B.R.; Mathews, J.H.; Mitchell, C.J.; Roehrig, J.T.; Wood, D.J.; Taffs, F.; Sil, B.K.; Whitby, S.N.; et al. Analysis of a yellow fever virus isolated from a fatal case of vaccine-associated human encephalitis. J. Infect. Dis. 1994, 169, 512-518.

89. McElroy, K.L.; Tsetsarkin, K.A.; Vanlandingham, D.L.; Higgs, S. Role of the yellow fever virus structural protein genes in viral dissemination from the Aedes aegypti mosquito midgut. J. Gen. Virol. 2006, 87, 2993-3001.

90. Miller, B.R.; Adkins, D. Biological characterization of plaque-size variants of yellow fever virus in mosquitoes and mice. Acta Virol. 1988, 32, 227-234.

91. Whitman, L. Failure of Aedes aegypti to transmit yellow fever cultured virus (17D). Am. J. Trop. Med. Hyg. 1939, 19, 19-26.

92. McElroy, K.L.; Tsetsarkin, K.A.; Vanlandingham, D.L.; Higgs, S. Characterization of an infectious clone of the wild-type yellow fever virus Asibi strain that is able to infect and disseminate in mosquitoes. J. Gen. Virol. 2005, 86, 1747-1751.

93. McElroy, K.L.; Tsetsarkin, K.A.; Vanlandingham, D.L.; Higgs, S. Manipulation of the yellow fever virus non-structural genes $2 \mathrm{~A}$ and $4 \mathrm{~B}$ and the $3^{\prime}$ non-coding region to evaluate genetic determinants of viral dissemination from the Aedes aegypti midgut. Am. J. Trop. Med. Hyg. 2006, 75, 1158-1164.

94. Huang, Y.J.; Nuckols, J.T.; Horne, K.M.; Vanlandingham, D.; Lobigs, M.; Higgs, S. Mutagenesis analysis of T380R mutation in the envelope protein of yellow fever virus. Virol. J. 2014, 11, 60 .

95. World Health Organization. Dengue: Guidelines for Diagnosis, Treatment, Prevention and Control: New Edition; WHO: Geneva, Switzerland, 2009.

96. Guzman, M.G.; Halstead, S.B.; Artsob, H.; Buchy, P.; Farrar, J.; Gubler, D.J.; Hunsperger, E.; Kroeger, A.; Margolis, H.S.; Martinez, E.; et al. Dengue: A continuing global threat. Nat. Rev. Microbiol. 2010, 8, S7-S16.

97. Centers for Disease Control and Prevention (CDC). Locally acquired dengue-Key West, Florida, 2009-2010. MMWR. Morb. Mortal. Wkly. Rep. 2010, 59, 577-581.

98. Murray, K.O.; Rodriguez, L.F.; Herrington, E.; Kharat, V.; Vasilakis, N.; Walker, C.; Turner, C.; Khuwaja, S.; Arafat, R.; Weaver, S.C.; et al. Identification of dengue fever cases in Houston, Texas, with evidence of autochthonous transmission between 2003 and 2005. Vector Borne Zoonotic Dis. 2013, 13, 835-845. 
99. Gubler, D.J.; Rosen, L. Variation among geographic strains of Aedes albopictus in susceptibility to infection with dengue viruses. Am. J. Trop. Med. Hyg. 1976, 25, 318-325.

100. Sriurairatna, S.; Bhamarapravati, N. Replication of dengue-2 virus in Aedes albopictus mosquitoes. An electron microscopic study. Am. J. Trop. Med. Hyg. 1977, 26, 1199-1205.

101. Yamamoto, N.; Kimura, T.; Ohyama, A. Multiplication and distribution of type 2 dengue and Japanese encephalitis viruses in Toxorhynchites splendens after intrathoracic inoculation. Arch. Virol. 1987, 97, 37-47.

102. Salazar, M.I.; Richardson, J.H.; Sanchez-Vargas, I.; Olson, K.E.; Beaty, B.J. Dengue virus type 2: Replication and tropisms in orally infected Aedes aegypti mosquitoes. BMC Microbiol. 2007, 7, 9.

103. Doi, R. Studies on the mode of development of Japanese encephalitis virus in some groups of mosquitoes by the fluorescent antibody technique. Jpn. J. Exp. Med. 1970, 40, 101-115.

104. Kinney, R.M.; Butrapet, S.; Chang, G.J.; Tsuchiya, K.R.; Roehrig, J.T.; Bhamarapravati, N.; Gubler, D.J. Construction of infectious cDNA clones for dengue 2 virus: Strain 16681 and its attenuated vaccine derivative, strain PDK-53. Virology 1997, 230, 300-308.

105. Butrapet, S.; Childers, T.; Moss, K.J.; Erb, S.M.; Luy, B.E.; Calvert, A.E.; Blair, C.D.; Roehrig, J.T.; Huang, C.Y. Amino acid changes within the E protein hinge region that affect dengue virus type 2 infectivity and fusion. Virology 2011, 413, 118-127.

106. Erb, S.M.; Butrapet, S.; Moss, K.J.; Luy, B.E.; Childers, T.; Calvert, A.E.; Silengo, S.J.; Roehrig, J.T.; Huang, C.Y.; Blair, C.D. Domain-III FG loop of the dengue virus type 2 envelope protein is important for infection of mammalian cells and Aedes aegypti mosquitoes. Virology 2010, 406, 328-335.

107. Hung, J.J.; Hsieh, M.T.; Young, M.J.; Kao, C.L.; King, C.C.; Chang, W. An external loop region of domain III of dengue virus type 2 envelope protein is involved in serotype-specific binding to mosquito but not mammalian cells. J. Virol. 2004, 78, 378-388.

108. Troyer, J.M.; Hanley, K.A.; Whitehead, S.S.; Strickman, D.; Karron, R.A.; Durbin, A.P.; Murphy, B.R. A live attenuated recombinant dengue-4 virus vaccine candidate with restricted capacity for dissemination in mosquitoes and lack of transmission from vaccinees to mosquitoes. Am. J. Trop. Med. Hyg. 2001, 65, 414-419.

109. Zust, R.; Dong, H.; Li, X.F.; Chang, D.C.; Zhang, B.; Balakrishnan, T.; Toh, Y.X.; Jiang, T.; Li, S.H.; Deng, Y.Q.; et al. Rational design of a live attenuated dengue vaccine: 2'-O-methyltransferase mutants are highly attenuated and immunogenic in mice and macaques. PLoS Pathog. 2013, 9, e1003521.

110. Xi, Z.; Ramirez, J.L.; Dimopoulos, G. The Aedes aegypti toll pathway controls dengue virus infection. PLoS Pathog. 2008, 4, e1000098.

111. Souza-Neto, J.A.; Sim, S.; Dimopoulos, G. An evolutionary conserved function of the JAK-STAT pathway in anti-dengue defense. Proc. Natl. Acad. Sci. USA 2009, 106, 17841-17846.

112. Ramirez, J.L.; Dimopoulos, G. The toll immune signaling pathway control conserved anti-dengue defenses across diverse Ae. aegypti strains and against multiple dengue virus serotypes. Dev. Comp. Immunol. 2010, 34, 625-629. 
113. Sanchez-Vargas, I.; Scott, J.C.; Poole-Smith, B.K.; Franz, A.W.; Barbosa-Solomieu, V.; Wilusz, J.; Olson, K.E.; Blair, C.D. Dengue virus type 2 infections of Aedes aegypti are modulated by the mosquito's RNA interference pathway. PLoS Pathog. 2009, 5, e1000299.

114. Sim, S.; Dimopoulos, G. Dengue virus inhibits immune responses in Aedes aegypti cells. PLoS One 2010, 5, e10678.

115. Lemaitre, B.; Kromer-Metzger, E.; Michaut, L.; Nicolas, E.; Meister, M.; Georgel, P.; Reichhart, J.M.; Hoffmann, J.A. A recessive mutation, immune deficiency (IMD), defines two distinct control pathways in the Drosophila host defense. Proc. Natl. Acad. Sci. USA 1995, 92, 9465-9469.

116. Ramirez, J.L.; Souza-Neto, J.; Torres Cosme, R.; Rovira, J.; Ortiz, A.; Pascale, J.M.; Dimopoulos, G. Reciprocal tripartite interactions between the Aedes aegypti midgut microbiota, innate immune system and dengue virus influences vector competence. PLoS Negl. Trop. Dis. 2012, 6, e1561.

117. Colpitts, T.M.; Cox, J.; Vanlandingham, D.L.; Feitosa, F.M.; Cheng, G.; Kurscheid, S.; Wang, P.; Krishnan, M.N.; Higgs, S.; Fikrig, E. Alterations in the Aedes aegypti transcriptome during infection with West Nile, dengue and yellow fever viruses. PLoS Pathog. 2011, 7, e1002189.

118. Behura, S.K.; Gomez-Machorro, C.; Harker, B.W.; deBruyn, B.; Lovin, D.D.; Hemme, R.R.; Mori, A.; Romero-Severson, J.; Severson, D.W. Global cross-talk of genes of the mosquito Aedes aegypti in response to dengue virus infection. PLoS Negl. Trop. Dis. 2011, $5, \mathrm{e} 1385$.

119. Sim, S.; Jupatanakul, N.; Ramirez, J.L.; Kang, S.; Romero-Vivas, C.M.; Mohammed, H.; Dimopoulos, G. Transcriptomic profiling of diverse Aedes aegypti strains reveals increased basal-level immune activation in dengue virus-refractory populations and identifies novel virus-vector molecular interactions. PLoS Negl. Trop. Dis. 2013, 7, e2295.

120. Sessions, O.M.; Barrows, N.J.; Souza-Neto, J.A.; Robinson, T.J.; Hershey, C.L.; Rodgers, M.A.; Ramirez, J.L.; Dimopoulos, G.; Yang, P.L.; Pearson, J.L.; et al. Discovery of insect and human dengue virus host factors. Nature 2009, 458, 1047-1050.

121. Bonizzoni, M.; Dunn, W.A.; Campbell, C.L.; Olson, K.E.; Marinotti, O.; James, A.A. Complex modulation of the Aedes aegypti transcriptome in response to dengue virus infection. PLoS One 2012, 7, e50512.

122. Kang, S.; Shields, A.R.; Jupatanakul, N.; Dimopoulos, G. Suppressing dengue-2 infection by chemical inhibition of Aedes aegypti host factors. PLoS Negl. Trop. Dis. 2014, 8, e3084.

123. Franz, A.W.; Sanchez-Vargas, I.; Adelman, Z.N.; Blair, C.D.; Beaty, B.J.; James, A.A.; Olson, K.E. Engineering RNA interference-based resistance to dengue virus type 2 in genetically modified Aedes aegypti. Proc. Natl. Acad. Sci. USA 2006, 103, 4198-4203.

124. Gaines, P.J.; Olson, K.E.; Higgs, S.; Powers, A.M.; Beaty, B.J.; Blair, C.D. Pathogen-derived resistance to dengue type 2 virus in mosquito cells by expression of the premembrane coding region of the viral genome. J. Virol. 1996, 70, 2132-2137.

125. Franz, A.W.; Sanchez-Vargas, I.; Piper, J.; Smith, M.R.; Khoo, C.C.; James, A.A.; Olson, K.E. Stability and loss of a virus resistance phenotype over time in transgenic mosquitoes harbouring an antiviral effector gene. Insect Mol. Biol. 2009, 18, 661-672. 
126. Phuc, H.K.; Andreasen, M.H.; Burton, R.S.; Vass, C.; Epton, M.J.; Pape, G.; Fu, G.; Condon, K.C.; Scaife, S.; Donnelly, C.A.; et al. Late-acting dominant lethal genetic systems and mosquito control. BMC Biol. 2007, 5, 11.

127. Walker, T.; Johnson, P.H.; Moreira, L.A.; Iturbe-Ormaetxe, I.; Frentiu, F.D.; McMeniman, C.J.; Leong, Y.S.; Dong, Y.; Axford, J.; Kriesner, P.; et al. The wMel Wolbachia strain blocks dengue and invades caged Aedes aegypti populations. Nature 2011, 476, 450-453.

128. Higgs, S.; Vanlandingham, D.L.; Klingler, K.A.; McElroy, K.L.; McGee, C.E.; Harrington, L.; Lang, J.; Monath, T.P.; Guirakhoo, F. Growth characteristics of Chimerivax ${ }^{\circledR}$-DEN vaccine viruses in Aedes aegypti and Aedes albopictus from Thailand. Am. J. Trop. Med. Hyg. 2006, 75, 986-993.

129. Mackenzie, J.S.; Barrett, A.D.T.; Deubel, V. The Japanese encephalitis serological group of flaviviruses: A brief introduction to the group. In Japanese Encephalitis and West Nile Viruses; Springer: New York, NY, USA, 2002.

130. Van den Hurk, A.F.; Ritchie, S.A.; Mackenzie, J.S. Ecology and geographical expansion of Japanese encephalitis virus. Ann. Rev. Entomol. 2009, 54, 17-35.

131. Current references in medical entomology from Russian, eastern European and Chinese literature. (Maryland. University. Dept. Of Zoology.). Available online: http://www.dtic.mil/ dtic/tr/fulltext/u2/629374.pdf (accessed on 4 June 2014).

132. Burke, D.S.; Tingpalapong, M.; Ward, G.S.; Andre, R.; Leake, C.J. Intense transmission of Japanese encephalitis virus to pigs in a region free of epidemic encephalitis. Southeast Asian J. Trop. Med. Public Health 1985, 16, 199-206.

133. Thein, S.; Aung, H.; Sebastian, A.A. Study of vector, amplifier, and human infection with Japanese encephalitis virus in a Rangoon community. Am. J. Epidemiol. 1988, 128, 1376-1382.

134. Campbell, G.L.; Hills, S.L.; Fischer, M.; Jacobson, J.A.; Hoke, C.H.; Hombach, J.M.; Marfin, A.A.; Solomon, T.; Tsai, T.F.; Tsu, V.D.; et al. Estimated global incidence of Japanese encephalitis: A systematic review. Bull. World Health Org. 2011, 89, 766-774.

135. Hanna, J.N.; Ritchie, S.A.; Phillips, D.A.; Shield, J.; Bailey, M.C.; Mackenzie, J.S.; Poidinger, M.; McCall, B.J.; Mills, P.J. An outbreak of Japanese encephalitis in the Torres Strait, Australia, 1995. Med. J. Aust. 1996, 165, 256-260.

136. Mackenzie, J.S.; Johansen, C.A.; Ritchie, S.A.; van den Hurk, A.F.; Hall, R.A. Japanese encephalitis as an emerging virus: The emergence and spread of Japanese encephalitis virus in Australasia. Curr. Top. Microbiol. Immunol. 2002, 267, 49-73.

137. Van Den Hurk, A.F.; Montgomery, B.L.; Northill, J.A.; Smith, I.L.; Zborowski, P.; Ritchie, S.A.; Mackenzie, J.S.; Smith, G.A. Short report: The first isolation of Japanese encephalitis virus from mosquitoes collected from mainland Australia. Am. J. Trop. Med. Hyg. 2006, 75, 21-25.

138. Prummongkol, S.; Panasoponkul, C.; Apiwathnasorn, C.; Lek-Uthai, U. Biology of Culex sitiens, a predominant mosquito in Phang Nga, Thailand after a tsunami. J. Insect Sci. 2012, 12, 11.

139. Vythilingam, I.; Tan, S.B.; Krishnasamy, M. Susceptibility of Culex sitiens to Japanese encephalitis virus in peninsular Malaysia. Trop. Med. Int. Health TM IH 2002, 7, 539-540.

140. Okuno, T.; Mitchell, C.J.; Chen, P.S.; Wang, J.S.; Lin, S.Y. Seasonal infection of Culex mosquitos and swine with Japanese encephalitis virus. Bull. World Health Org. 1973, 49, $347-352$. 
141. Buescher, E.L.; Scherer, W.F. Ecologic studies of Japanese encephalitis virus in Japan. IX. Epidemiologic correlations and conclusions. Am. J. Trop. Med. Hyg. 1959, 8, 719-722.

142. Harbach, R.E. Classification within the cosmopolitan genus Culex (Diptera: Culicidae): The foundation for molecular systematics and phylogenetic research. Acta Trop. 2011, 120, 1-14.

143. Olson, J.G.; Ksiazek, T.G.; Lee, V.H.; Tan, R.; Shope, R.E. Isolation of Japanese encephalitis virus from Anopheles annularis and Anopheles vagus in Lombok, Indonesia. Trans. R. Soc. Trop. Med. Hyg. 1985, 79, 845-847.

144. Weng, M.H.; Lien, J.C.; Wang, Y.M.; Lin, C.C.; Lin, H.C.; Chin, C. Isolation of Japanese encephalitis virus from mosquitoes collected in northern Taiwan between 1995 and 1996. J. Microbiol. Immunol. Infect. 1999, 32, 9-13.

145. Van den Hurk, A.F.; Johansen, C.A.; Zborowski, P.; Paru, R.; Foley, P.N.; Beebe, N.W.; Mackenzie, J.S.; Ritchie, S.A. Mosquito host-feeding patterns and implications for Japanese encephalitis virus transmission in northern Australia and Papua New Guinea. Med. Vet. Entomol. 2003, 17, 403-411.

146. Pennington, N.E.; Phelps, C.A. Identification of the host range of Culex tritaeniorhynchus mosquitoes on Okinawa, Ryukyu islands. J. Med. Entomol. 1968, 5, 483-487.

147. Philip Samuel, P.; Arunachalam, N.; Hiriyan, J.; Tyagi, B.K. Host feeding pattern of Japanese encephalitis virus vector mosquitoes (Diptera: Culicidae) from Kuttanadu, Kerala, India. J. Med. Entomol. 2008, 45, 927-932.

148. Takahashi, M.; Suzuki, K. Japanese encephalitis virus in mosquito salivary glands. Am. J. Trop. Med. Hyg. 1979, 28, 122-135.

149. Gould, D.J.; Barnett, H.C.; Suyemoto, W. Transmission of Japanese encephalitis virus by Culex gelidus theobald. Trans. R. Soc. Trop. Med. Hyg. 1962, 56, 429-435.

150. Muangman, D.; Edelman, R.; Sullivan, M.J.; Gould, D.J. Experimental transmission of Japanese encephalitis virus by Culex fuscocephala. Am. J. Trop. Med. Hyg. 1972, 21, 482-486.

151. Rosen, L.; Tesh, R.B.; Lien, J.C.; Cross, J.H. Transovarial transmission of Japanese encephalitis virus by mosquitoes. Science 1978, 199, 909-911.

152. Rosen, L.; Shroyer, D.A.; Lien, J.C. Transovarial transmission of Japanese encephalitis virus by Culex tritaeniorhynchus mosquitoes. Am. J. Trop. Med. Hyg. 1980, 29, 711-712.

153. Chen, B.Q.; Beaty, B.J. Japanese encephalitis vaccine (2-8 strain) and parent (SA14 strain) viruses in Culex tritaeniorhynchus mosquitoes. Am. J. Trop. Med. Hyg. 1982, 31, 403-407.

154. Reid, M.; Mackenzie, D.; Baron, A.; Lehmann, N.; Lowry, K.; Aaskov, J.; Guirakhoo, F.; Monath, T.P. Experimental infection of Culex annulirostris, Culex gelidus, and Aedes vigilax with a yellow fever/Japanese encephalitis virus vaccine chimera (ChimeriVax ${ }^{\mathrm{TM}_{-} \mathrm{JE}}$ ). Am. J. Trop. Med. Hyg. 2006, 75, 659-663.

155. Whitehead, S.S.; Hanley, K.A.; Blaney, J.E., Jr.; Gilmore, L.E.; Elkins, W.R.; Murphy, B.R. Substitution of the structural genes of dengue virus type 4 with those of type 2 results in chimeric vaccine candidates which are attenuated for mosquitoes, mice, and rhesus monkeys. Vaccine 2003, 21, 4307-4316.

156. Yamshchikov, V.; Mishin, V.; Cominelli, F. A new strategy in design of +RNA virus infectious clones enabling their stable propagation in E. coli. Virology 2001, 281, 272-280. 
157. Sumiyoshi, H.; Hoke, C.H.; Trent, D.W. Infectious Japanese encephalitis virus RNA can be synthesized from in vitro-ligated cDNA templates. J. Virol. 1992, 66, 5425-5431.

158. Zhao, Z.; Date, T.; Li, Y.; Kato, T.; Miyamoto, M.; Yasui, K.; Wakita, T. Characterization of the E-138 (Glu/Lys) mutation in Japanese encephalitis virus by using a stable, full-length, infectious cDNA clone. J. Gen. Virol. 2005, 86, 2209-2220.

159. Yun, S.I.; Kim, S.Y.; Rice, C.M.; Lee, Y.M. Development and application of a reverse genetics system for Japanese encephalitis virus. J. Virol. 2003, 77, 6450-6465.

160. Pu, S.Y.; Wu, R.H.; Yang, C.C.; Jao, T.M.; Tsai, M.H.; Wang, J.C.; Lin, H.M.; Chao, Y.S.; Yueh, A. Successful propagation of flavivirus infectious cDNAs by a novel method to reduce the cryptic bacterial promoter activity of virus genomes. J. Virol. 2011, 85, 2927-2941.

161. Pedersen, C.E., Jr.; Robinson, D.M.; Cole, F.E., Jr. Isolation of the vaccine strain of Venezuelan equine encephalomyelitis virus from mosquitoes in Louisiana. Am. J. Epidemiol. 1972, 95, 490-496.

162. Reeves, W.C.; Hammon, W.M.; Technical Assistance of Griselda, G.W.; Carlos, E. Laboratory transmission of Japanese B encephalitis virus by seven species (three genera) of North American mosquitoes. J. Exp. Med. 1946, 83, 185-194.

163. Smithburn, K.C.; Hughes, T.P.; Burke, A.W.; Paul, J.H. A neurotropic virus isolated from the blood of a native of Uganda. Am. J. Trop. Med. Hyg. 1940, 1, 471-492.

164. Cleton, N.; Koopmans, M.; Reimerink, J.; Godeke, G.J.; Reusken, C. Come fly with me: Review of clinically important arboviruses for global travelers. J. Clin. Virol. 2012, 55, 191-203.

165. Gray, T.J.; Webb, C.E. A review of the epidemiological and clinical aspects of West Nile virus. Int. J. Gen. Med. 2014, 7, 193-203.

166. Kilpatrick, A.M. Globalization, land use, and the invasion of West Nile virus. Science 2011, 334, 323-327.

167. Reiter, P. West Nile virus in Europe: Understanding the present to gauge the future. Euro Surveill. 2010, 15, 19508.

168. Andreadis, T.G.; Anderson, J.F.; Vossbrinck, C.R. Mosquito surveillance for West Nile virus in Connecticut, 2000: Isolation from Culex pipiens, Cx. restuans, $C x$. salinarius, and Culiseta melanura. Emerg. Infect. Dis. 2001, 7, 670-674.

169. Turell, M.J.; O’Guinn, M.; Oliver, J. Potential for New York mosquitoes to transmit West Nile virus. Am. J. Trop. Med. Hyg. 2000, 62, 413-414.

170. Sardelis, M.R.; Turell, M.J. Ochlerotatus j. japonicus in Frederick County, Maryland: Discovery, distribution, and vector competence for West Nile virus. J. Am. Mosq. Control Assoc. 2001, 17, 137-141.

171. Weaver, S.C.; Barrett, A.D. Transmission cycles, host range, evolution and emergence of arboviral disease. Nat. Rev. Microbiol. 2004, 2, 789-801.

172. Arensburger, P.; Megy, K.; Waterhouse, R.M.; Abrudan, J.; Amedeo, P.; Antelo, B.; Bartholomay, L.; Bidwell, S.; Caler, E.; Camara, F.; et al. Sequencing of Culex quinquefasciatus establishes a platform for mosquito comparative genomics. Science 2010, 330, 86-88.

173. Higgs, S.; Schneider, B.S.; Vanlandingham, D.L.; Klingler, K.A.; Gould, E.A. Nonviremic transmission of West Nile virus. Proc. Natl. Acad. Sci. USA 2005, 102, 8871-8874. 
174. Reisen, W.K.; Fang, Y.; Martinez, V. Is nonviremic transmission of West Nile virus by Culex mosquitoes (Diptera: Culicidae) nonviremic? J. Med. Entomol. 2007, 44, 299-302.

175. Styer, L.M.; Kent, K.A.; Albright, R.G.; Bennett, C.J.; Kramer, L.D.; Bernard, K.A. Mosquitoes inoculate high doses of West Nile virus as they probe and feed on live hosts. PLoS Pathog. 2007, 3, 1262-1270.

176. McGee, C.E.; Schneider, B.S.; Girard, Y.A.; Vanlandingham, D.L.; Higgs, S. Nonviremic transmission of West Nile virus: Evaluation of the effects of space, time, and mosquito species. Am. J. Trop. Med. Hyg. 2007, 76, 424-430.

177. Vanlandingham, D.L.; McGee, C.E.; Klingler, K.A.; Galbraith, S.E.; Barrett, A.D.; Higgs, S. Short report: Comparison of oral infectious dose of West Nile virus isolates representing three distinct genotypes in Culex quinquefasciatus. Am. J. Trop. Med. Hyg. 2008, 79, 951-954.

178. Wicker, J.A.; Whiteman, M.C.; Beasley, D.W.; Davis, C.T.; Zhang, S.; Schneider, B.S.; Higgs, S.; Kinney, R.M.; Barrett, A.D. A single amino acid substitution in the central portion of the West Nile virus NS4B protein confers a highly attenuated phenotype in mice. Virology 2006, 349, 245-253.

179. Wicker, J.A.; Whiteman, M.C.; Beasley, D.W.; Davis, C.T.; McGee, C.E.; Lee, J.C.; Higgs, S.; Kinney, R.M.; Huang, C.Y.; Barrett, A.D. Mutational analysis of the West Nile virus NS4B protein. Virology 2012, 426, 22-33.

180. Van Slyke, G.A.; Ciota, A.T.; Willsey, G.G.; Jaeger, J.; Shi, P.Y.; Kramer, L.D. Point mutations in the West Nile virus (Flaviviridae; Flavivirus) RNA-dependent RNA polymerase alter viral fitness in a host-dependent manner in vitro and in vivo. Virology 2012, 427, 18-24.

181. Mason, P.W. Maturation of Japanese encephalitis virus glycoproteins produced by infected mammalian and mosquito cells. Virology 1989, 169, 354-364.

182. Ye, Q.; Li, X.F.; Zhao, H.; Li, S.H.; Deng, Y.Q.; Cao, R.Y.; Song, K.Y.; Wang, H.J.; Hua, R.H.; $\mathrm{Yu}, \mathrm{Y} . \mathrm{X}$; et al. A single nucleotide mutation in NS2A of Japanese encephalitis-live vaccine virus (SA14-14-2) ablates NS1' formation and contributes to attenuation. J. Gen. Virol. 2012, 93, 1959-1964.

183. Firth, A.E.; Atkins, J.F. A conserved predicted pseudoknot in the NS2A-encoding sequence of West Nile and Japanese encephalitis flaviviruses suggests NS1' may derive from ribosomal frameshifting. Virol. J. 2009, 6, 14.

184. Melian, E.B.; Hall-Mendelin, S.; Du, F.; Owens, N.; Bosco-Lauth, A.M.; Nagasaki, T.; Rudd, S.; Brault, A.C.; Bowen, R.A.; Hall, R.A.; et al. Programmed ribosomal frameshift alters expression of West Nile virus genes and facilitates virus replication in birds and mosquitoes. PLoS Pathog. 2014, 10, e1004447.

185. Van Slyke, G.A.; Jia, Y.; Whiteman, M.C.; Wicker, J.A.; Barrett, A.D.; Kramer, L.D. Vertebrate attenuated West Nile virus mutants have differing effects on vector competence in Culex tarsalis mosquitoes. J. Gen. Virol. 2013, 94, 1069-1072.

186. Farajollahi, A.; Crans, W.J.; Bryant, P.; Wolf, B.; Burkhalter, K.L.; Godsey, M.S.; Aspen, S.E.; Nasci, R.S. Detection of West Nile viral RNA from an overwintering pool of Culex pipens pipiens (Diptera: Culicidae) in New Jersey, 2003. J. Med. Entomol. 2005, 42, 490-494. 
187. Girard, Y.A.; Schneider, B.S.; McGee, C.E.; Wen, J.; Han, V.C.; Popov, V.; Mason, P.W.; Higgs, S. Salivary gland morphology and virus transmission during long-term cytopathologic West Nile virus infection in Culex mosquitoes. Am. J. Trop. Med. Hyg. 2007, 76, 118-128.

188. Vanlandingham, D.L.; Schneider, B.S.; Klingler, K.; Fair, J.; Beasley, D.; Huang, J.; Hamilton, P.; Higgs, S. Real-time reverse transcriptase-polymerase chain reaction quantification of West Nile virus transmitted by Culex pipiens quinquefasciatus. Am. J. Trop. Med. Hyg. 2004, 71, 120-123.

189. Monath, T.P. The Arboviruses: Epidemiology and Ecology; CRC Press: Boca Raton, FL, USA, 1988.

190. Mishra, A.C.; Mourya, D.T. Transovarial transmission of West Nile virus in Culex vishnui mosquito. Indian J. Med. Res. 2001, 114, 212-214.

191. Goddard, L.B.; Roth, A.E.; Reisen, W.K.; Scott, T.W. Vertical transmission of West Nile virus by three California Culex (Diptera: Culicidae) species. J. Med. Entomol. 2003, 40, 743-746.

192. Brackney, D.E.; Beane, J.E.; Ebel, G.D. RNAi targeting of West Nile virus in mosquito midguts promotes virus diversification. PLoS Pathog. 2009, 5, e1000502.

193. Chotkowski, H.L.; Ciota, A.T.; Jia, Y.; Puig-Basagoiti, F.; Kramer, L.D.; Shi, P.Y.; Glaser, R.L. West Nile virus infection of Drosophila melanogaster induces a protective RNAi response. Virology 2008, 377, 197-206.

194. Arjona, A.; Wang, P.; Montgomery, R.R.; Fikrig, E. Innate immune control of West Nile virus infection. Cell. Microbiol. 2011, 13, 1648-1658.

195. Paradkar, P.N.; Trinidad, L.; Voysey, R.; Duchemin, J.B.; Walker, P.J. Secreted Vago restricts West Nile virus infection in Culex mosquito cells by activating the JAK-STAT pathway. Proc. Natl. Acad. Sci. USA 2012, 109, 18915-18920.

196. Schneider, B.S.; Higgs, S. The enhancement of arbovirus transmission and disease by mosquito saliva is associated with modulation of the host immune response. Trans. R. Soc. Trop. Med. Hyg. 2008, 102, 400-408.

197. Schneider, B.S.; Soong, L.; Girard, Y.A.; Campbell, G.; Mason, P.; Higgs, S. Potentiation of West Nile encephalitis by mosquito feeding. Viral Immunol. 2006, 19, 74-82.

198. Wanasen, N.; Nussenzveig, R.H.; Champagne, D.E.; Soong, L.; Higgs, S. Differential modulation of murine host immune response by salivary gland extracts from the mosquitoes Aedes aegypti and Culex quinquefasciatus. Med. Vet. Entomol. 2004, 18, 191-199.

199. Anderson, J.F.; Main, A.J.; Cheng, G.; Ferrandino, F.J.; Fikrig, E. Horizontal and vertical transmission of West Nile virus genotype NY99 by Culex salinarius and genotypes NY99 and WN02 by Culex tarsalis. Am. J. Trop. Med. Hyg. 2012, 86, 134-139.

(C) 2014 by the authors; licensee MDPI, Basel, Switzerland. This article is an open access article distributed under the terms and conditions of the Creative Commons Attribution license (http://creativecommons.org/licenses/by/4.0/). 